\title{
Polar baseline surface radiation measurements during the International Polar Year 2007-2009
}

\author{
C. Lanconelli ${ }^{1}$, M. Busetto ${ }^{1}$, E. G. Dutton ${ }^{2}$, G. König-Langlo ${ }^{3}$, M. Maturilli ${ }^{3}$, R. Sieger ${ }^{3}$, V. Vitale ${ }^{1}$, and \\ T. Yamanouchi ${ }^{4}$ \\ ${ }^{1}$ Institute of Atmospheric Sciences and Climate, Bologna, Italy \\ ${ }^{2}$ National Oceanic and Atmospheric Administration, Boulder, Colorado, USA \\ ${ }^{3}$ Alfred Wegener Institute, Bremerhaven, Germany \\ ${ }^{4}$ National Institute of Polar Research, Tokyo, Japan
}

Received: 27 August 2010 - Published in Earth Syst. Sci. Data Discuss.: 22 September 2010

Revised: 15 December 2010 - Accepted: 17 December 2010 - Published: 14 January 2011

\begin{abstract}
Downwelling and upwelling shortwave and longwave radiation components from six active polar sites, taking part of the Baseline Surface Radiation Network (BSRN), were selected for the period of the last International Polar Year (March 2007 to March 2009), and included in the BSRN-IPY dataset, along with metadata and supplementary data for some of the stations. Two sites, located at Svalbard archipelago (Ny Ålesund) and Alaska (Barrow), represent Arctic sea-level conditions. Four Antarctic stations represent both sea-level (Dronning Maud Land and Cosmonaut Sea) and high-elevation conditions (South Pole and East Antarctic Plateau). The BSRN-IPY dataset content and quality are discussed. The dataset is now available at doi:10.1594/PANGAEA.737668, and can be used for free after accepting the BSRN data release guidelines. The dataset has been summarized as monthly averages and subject to further evaluation according to strict criteria not previously applied.
\end{abstract}

\section{Introduction}

The radiative energy budget at the surface plays a fundamental role in defining the thermal conditions and drives the general circulation of the earth-atmosphere system, shaping the main characteristics of the earth's climate. To provide the scientific community with a high quality surface shortwave and terrestrial radiation monitoring, the Baseline Surface Radiation Network (BSRN, http://bsrn.awi.de), was established in 1988, under the oversight of the GEWEX Radiation Panel (www.gewex.org). The BSRN provides accurate measurement of surface radiation fluxes collected at 51 sites around the world. The project provides structure and general guidance to a select group of international observing sites, whose leaders voluntarily contribute their efforts and data to a central data archive. A set of associated requirements and specifications (Heimo et al., 1993; Ohmura et al., 1998; Hegner et al., 1998; McArthur, 2004) as well as the overall goals have been subject to review and revision as new needs, capabil-

Correspondence to: C. Lanconelli (c.lanconelli@isac.cnr.it) ities and technology appear. The network has grown from nine reporting sites in 1992 to 51 in 2010. There are about 20 additional sites that have indicated an intent to participate and may be able to provide both prior and current data (Dutton and Erlich, 2010).

Four high latitude sites have operated since BSRN was established in 1992 in both the Arctic (Ny Ålesund and Barrow) and the Antarctic (Amundsen-Scott and Neumayer). Two additional Antarctic sites have archived data since 1994 (Syowa) and 2006 (Dome C).

Radiation measurements at high latitudes are especially affected by problems due to rime deposition, snow accumulation, solar tracker failures, and calibration temperature compensation. A working group entitled Cold Climate Issues was established during the 10th BSRN Scientific Review and Workshop held in De Bild (Netherland) during 2008, in order to address and minimize the impact of these problems in BSRN polar data (Dutton, 2008).

A subset of the BSRN archived data was prepared at the request of IPY participants so that these data would be uniformly evaluated and made available for IPY applications. Although the data are routinely acquired and available at the BSRN archive, this paper provides additional evaluation and 
Table 1. List of the BSRN stations covered by the dataset, BSRN station identifier and number and abbreviation (st_n/st_id), coordinates, surface and topography type. Basic measurements of radiation (B), Expanded measurements (E), Meteorological synoptic observations (M), Ozone measurements $(\mathrm{O})$, and Radiosonde measurements $(\mathrm{R})$.

\begin{tabular}{lccrrrlll}
\hline Site & st_n & st_id & LAT $^{\circ}$ & LON $^{\circ}$ & Alt(mt) & Surface type & Topography type & Data type \\
\hline Ny Ålesund & 11 & nya & 78.925 & 11.950 & 11 & Tundra & Mt. valley, rural & B,E,M,O,R \\
Barrow & 22 & bar & 71.323 & -156.607 & 8 & Tundra & flat, rural & B \\
Syowa & 17 & syo & -69.005 & 39.589 & 18 & Sea Ice & hilly, rural & B,M,O,R \\
G. von Neumayer & 13 & gvn & -70.650 & -8.250 & 42 & Iceshelf & flat, rural & B,E,M,O,R \\
Dome C & 74 & dom & -75.100 & 123.383 & 3233 & Glacier, accum. & flat rural & B \\
South Pole & 26 & spo & -89.983 & -24.799 & 2800 & Glacier, accum. & flat rural & B \\
\hline
\end{tabular}
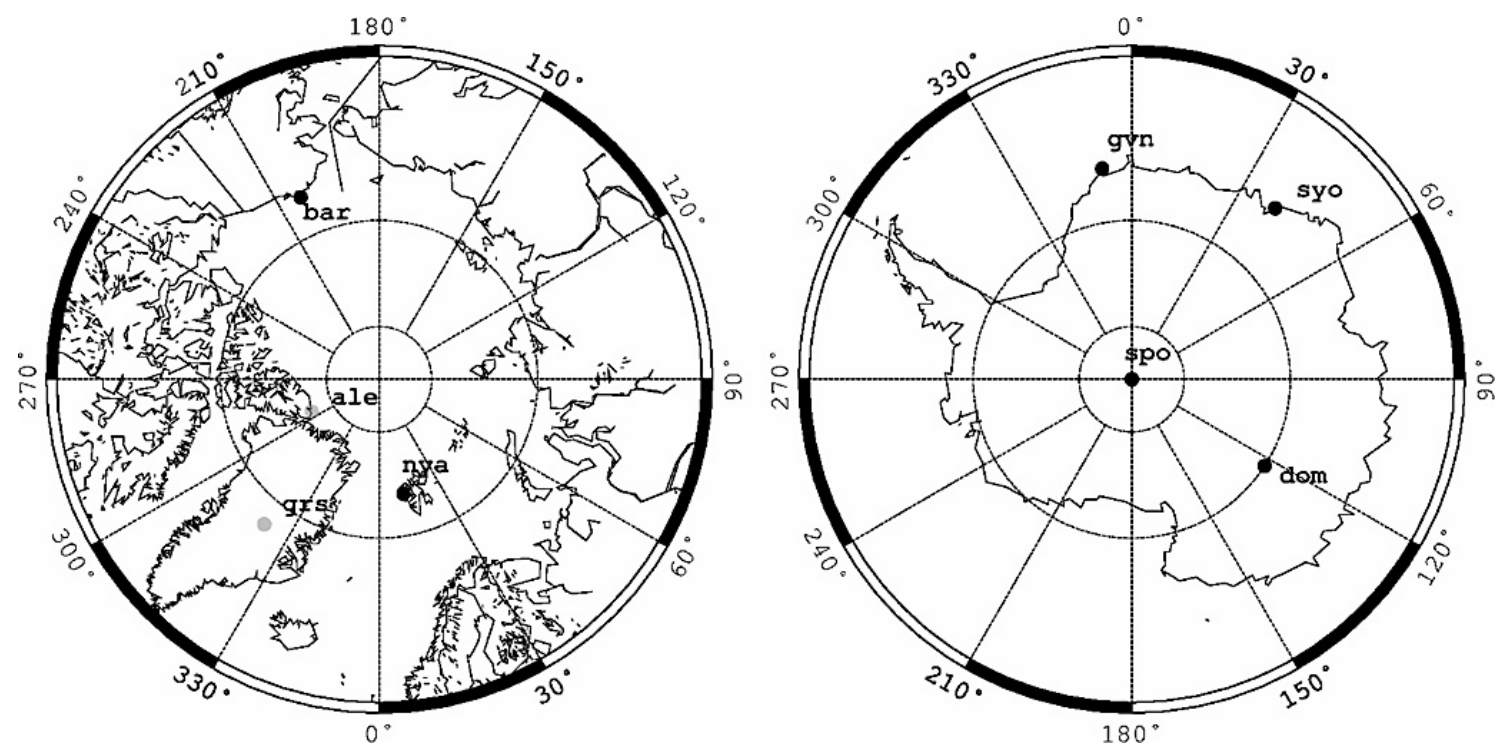

Figure 1. Position of the BSRN-IPY polar station (black), along with BSRN stations in pending status (gray).

summary of the data that will be of interest to IPY participants and others who wish to focus their research on the polar regions. In this paper we highlight certain observational and data evaluation issues specific to the extreme polar conditions.

\section{BSRN-IPY dataset description}

The BSRN-IPY dataset contains many continuously measured top-quality broadband surface radiation fluxes, averaged over one minute, collected by BSRN polar stations from March 2007 to March 2009, coincident to the IPY intensive field experiment (http://ipy.arcticportal.org). Description of the BSRN polar stations contributing data to this dataset are indicated in Table 1. Four of them are operating in Antarctica at both coastal (Syowa $69^{\circ} \mathrm{S}$, and Neumayer $71^{\circ} \mathrm{S}$ ) and high plateau (Amundsen-Scott $90^{\circ} \mathrm{S}$ and Dome $\mathrm{C} 75^{\circ} \mathrm{S}$ ) positions. The remaining two stations, Ny Ålesund $79^{\circ} \mathrm{N}$ and Barrow $71^{\circ} \mathrm{N}$, represent northern polar conditions at sea level, from Svalbard archipelago and Alaska respec- tively. Geographic position of the operating BSRN stations included in this dataset, and of two additional stations not included in this dataset because in a pending status (Alert $83^{\circ} \mathrm{N}$ and Greenland Summit $73^{\circ} \mathrm{N}$ ), are given in Fig. 1.

The basic set of measurements to be implemented in order to be part of the network, consists of the downwelling components of the solar and longwave radiations. The global, diffuse and direct components of the solar radiation have to be measured with independent instruments. This is a common set of measurements for all the BSRN sites. Some of them also have an expanded set of measurement composed of the upwelling shortwave and longwave components (Ny Ålesund and Neumayer). Additionally supplementary datasets like synoptic observations, upper air soundings, ozone values and ceilometer data are given for a few stations ( $\mathrm{Ny}$ Ålesund, Neumayer $71^{\circ} \mathrm{S}$ and Syowa $69^{\circ} \mathrm{S}$ ).

Other stations measure upwelling components of SW and LW (Dome C and Amundsen-Scott), but were not submitted to archive when the present release of the BSRN-IPY dataset was compiled. Interested users are requested to check for 


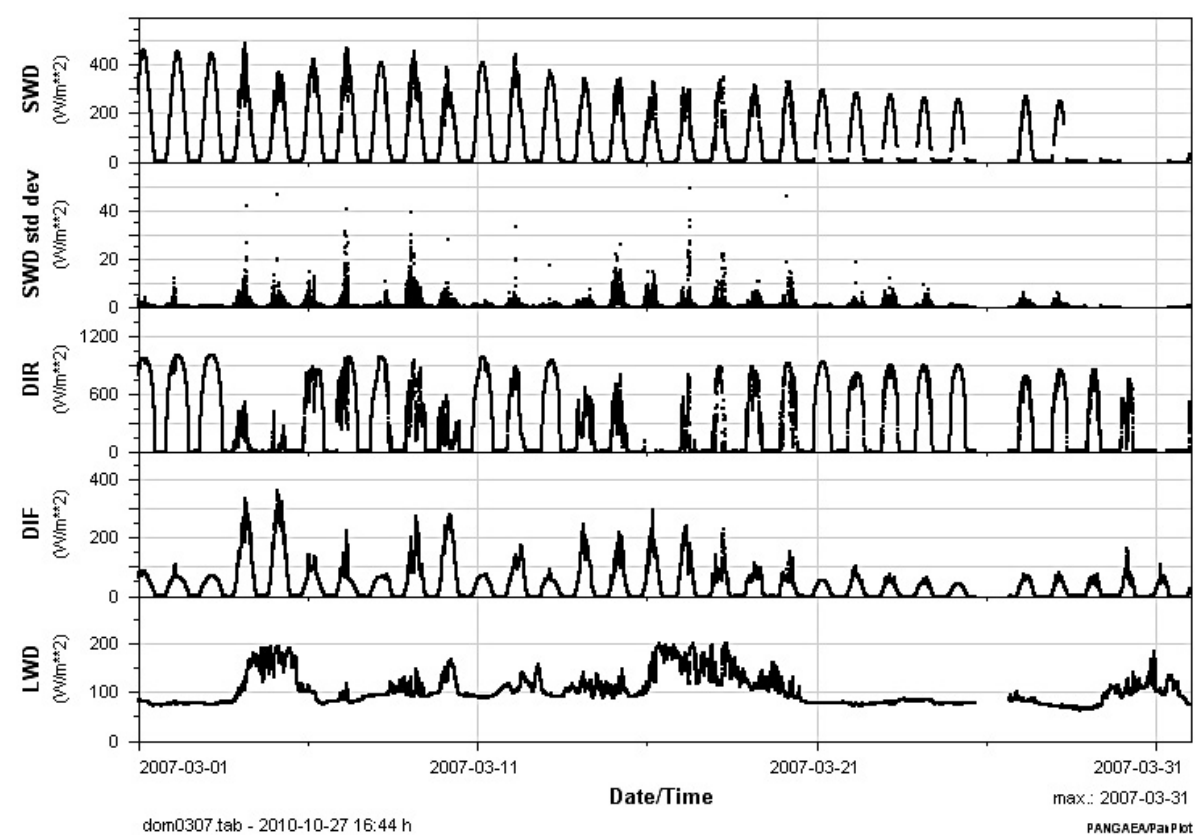

Figure 2. Example of PanPlot at work. It is free tool developed for time series visualization of data stored in PANGAEA archive format. In this example the downwelling components SWD, DIR, DIF and LWD, and the standard deviation of the global shortwave are shown for March 2007 at Dome C.

updates in order to obtain these additional radiation components.

The BSRN-IPY dataset consists of 150 station-months of basic downwelling radiation data given in tab-delimited textfile. The file contains average, standard deviation, maximum and minimum reported with the time resolution of one minute. Additionally, there are 50 station-months of upwelling components of short-wave and long-wave radiation given with the same time resolution, 75 monthly files containing surface synoptic observations obtained from collocated meteorological stations, 50 monthly files containing ozone soundings and 50 monthly files containing radiosonde measurements. Table 1 reports the detailed list of data available.

Each textfile includes all necessary metadata. No special software is needed to access the data but it is suggested to have a look at software offered by PANGAEA to convert (Pan2Applic, doi:10.1594/PANGAEA.288115) or visualize the data (PanPlot, doi:10.1594/PANGAEA.330147). In particular, the PanPlot tool is suitable for the visualization of time patterns of data and multivariate analysis (Fig. 2).

\subsection{Data access}

The dataset is composed of a subset of monthly files archived in the World Radiation Monitoring Center (WRMC) the central archive of the BSRN - hosted at Alfred Wegener Institute (http://bsrn.awi.de). All these independent monthly archives, were joined into a parent dataset, see
doi:10.1594/PANGAEA.737668. The access to all metadata of the BSRN-IPY datasets is free, nevertheless the full access, available at doi:10.1594/PANGAEA.737668 is subject to BSRN data release guidelines (http://bsrn.awi.de). Any user who accepts them may ask, through a dedicated web section, to obtain an account to download more than 400 doi referenced datasets, directly through listed links or via ftp. Alternatively the dataset could be downloaded using the dedicated PANGAEA tool BSRN Toolbox available at doi:10.1594/PANGAEA.744019.

\section{Instruments and methods}

All radiation measurements are acquired using primary instruments, with a minimum sampling frequency of $1 \mathrm{~Hz}$ and stored at least as minute averages along with their standard deviation, maximum and minimum. Basic meteorological parameters such as air temperature $T_{\mathrm{a}}$, relative humidity $\mathrm{RH}$, and pressure $p$ should be included in the radiation file. Pyranometers and pyrgeometers should be ventilated. The body temperature $T_{\mathrm{b}}$ and whenever possible the dome temperature $T_{\mathrm{d}}$ of a shaded pyrgeometer should be collected to allow calculation of the longwave component using the correction given by Philipona et al. (1995). Corrections of the pyranometers shortwave measurements should be performed for (i) the thermal offsets, (ii) the cosine response, and (iii) the temperature sensitivity of the calibration constant; these corrections should be applied following BSRN guidelines (McArthur, 2004). 
All measurements performed within the BSRN are expected to be of high-quality and traceable with the World Radiometric Reference (WRR) standards for solar data and the World Infrared Standard Group (WISG) for infrared. However, differences between the precision of various components should be expected. The goals of the network with respect to absolute errors vary between components. The most accurate measurement implemented could be considered the shaded diffuse pyranometer (DIF) that is expected to be affected by an error of no more than $\pm 5 \mathrm{~W} / \mathrm{m}^{2}$ when the thermal offset is properly accounted for; the direct normal component $\mathrm{DIR}_{\perp}$, is expected to be associated with an absolute error of \pm 5 to $\pm 10 \mathrm{~W} / \mathrm{m}^{2}$ at most of BSRN sites, where windowed pyrheliometer were deployed; the global unshadowed pyranometer (global 2 or G2) is expected to be affected by errors up to $\pm 20 \mathrm{~W} / \mathrm{m}^{2}$ (Ohmura et al., 1998). The global measurement, performed with a ventilated and unshaded first-class pyranometer, is affected by substantial cosine error in presence of the direct SW component, while for diffuse this error is reduced to an averaged cosine error over all incoming hemispherical directions. Moreover, the diffuse component is weakly dependent on leveling errors relative to the global. All shortwave components are referenced to the World Radiometric Reference (WRR). It is valid for both pyrheliometer and pyranometers being the latter calibrated with respect to the WRR set of pyrheliometers with the shading-unshading method (McArthur, 2004). Using the BSRN-IPY dataset the downwelling shortwave global radiation (SWD) could be obtained from the pyranometer (global 2 or G2), or calculated as sum of the diffuse (DIF) and the direct normal $\left(\mathrm{DIR}_{\perp}\right)$ component, the latter weighted by the cosine of the solar zenith angle $\theta$ (McArthur, 2005; Michalsky, 1988),

$$
\mathrm{G} 1=\mathrm{DIF}+\cos \theta \mathrm{DIR}_{\perp}
$$

Global 1, calculated using Eq. (1), is expected to be more accurate and should be preferred e.g. for intercomparisons with instantaneous data from models or satellites. On the other hand, it is better to use Global 2 for averages and trends, since it normally has less missing values than G1, which requires continuity in solar tracker operation and gets data from two independent instruments. Longwave downwelling measurements performed with shaded and ventilated top-class pyrgeometers are expected to be affected by an error not greater than $\pm 10 \mathrm{~W} / \mathrm{m}^{2}$ (Ohmura et al., 1998). All instruments are traceable to the WISG hosted at Physikalisch-Meteorologisches Observatorium Davos/World Radiation Center (PMOD/WRC, Davos, Switzerland). The efforts of the BSRN community and in particular those of the PMOD/WRC, strive for the best definition of a standard measurements using black-body cavities BB1995 and BB2007 as reference, which have emissivities of near 1.00 (0.9999 and 0.9985).

All instruments used during the BSRN-IPY are idicated in each monthly file header and the WMO traceability can
Table 2. Set of instruments adopted by various stations for the various components. The "Repl" column indicates how many times a set of the same type was completely or partially replaced. gvn replaced CM11 with CM22 on February 2009. spo replaced just pyrgeometer. syo replaced pyrheliometer many times along the IPY period. Details are given in the metadata of the datasets.

\begin{tabular}{llllllll}
\hline Site & SWD & DIR & DIF & LWD & SWU & LWU & Repl \\
\hline bar & PSP & NIP & PSP & PIR & PSP & PIR & 1 \\
dom & CM22 & CH1 & CM22 & CG4 & - & - & 0 \\
gvn & CM11 & NIP & CM11 & PIR & CM11 & PIR & 5 \\
gvn & CM22 & NIP & CM22 & PIR & CM22 & PIR & - \\
nya & CM11 & NIP & CM11 & PIR & CM11 & PIR & 2 \\
spo & PSP & NIP & PSP & PIR & PSP & PIR & 1 \\
syo & CM21 & CH1 & CM21 & CG4 & CM21 & CG4 & 10 \\
\hline
\end{tabular}

be identified. A summary of the instrument types used at 6 stations for the various radiative components is given in Table 2. All instruments are manufactured by Kipp and Zonen or Eppley Laboratory, Inc. Sites managed by the Japan (syo) and Italy (dom) use Kipp and Zonen radiometers for both shortwave and longwave fluxes, German sites ( $g v n, n y a)$ use Kipp and Zonen radiometers for SW while they use Eppley PIR for LW. In Amundsen-Scott (spo) and Barrow (bar) sites, managed by NOAA, instruments from Eppley are used for both longwave and shortwave measurements. Stations gvn and syo exanchanged instruments for purpose of updating their calibration several times along the IPY period, spo, nya and bar exchanged instruments one time, following the guidelines of the network, while dom used the same set of instruments for the entire period.

Figure 3 shows a monthly time series of data availability for global 2, direct, diffuse and longwave downwelling components for each station. The percentages are calculated with respect to the maximum available number of minutes per month with a solar zenith angle $\theta<90^{\circ}$ for shortwave components, and for full 24-h days for the longwave. Some stations does not provide nightime values related to SW radiation components, flagging those in the archive data file. Hence, the fraction of shortwave available data was not reported during polar nights, although most sites report a valid number that could be used to check for some residual offset presented by pyrheliometers and pyranometers, being values greater than $-4 \mathrm{~W} / \mathrm{m}^{2}$ satisfactory for BSRN requirements (Table 3). Some loss of data is seen at the dom and bar sites, while shortwave measurements are incomplete during some months for dom and syo. Such problems are typically related to technical failures in the data acquisition system or tracker failures, and to data quality checks.

\section{Quality control tests and data summary}

All radiation data are subjected to quality control (QC) tests that were not made centrally in the World Radiation 
Data availability of the six BSRN polar stations

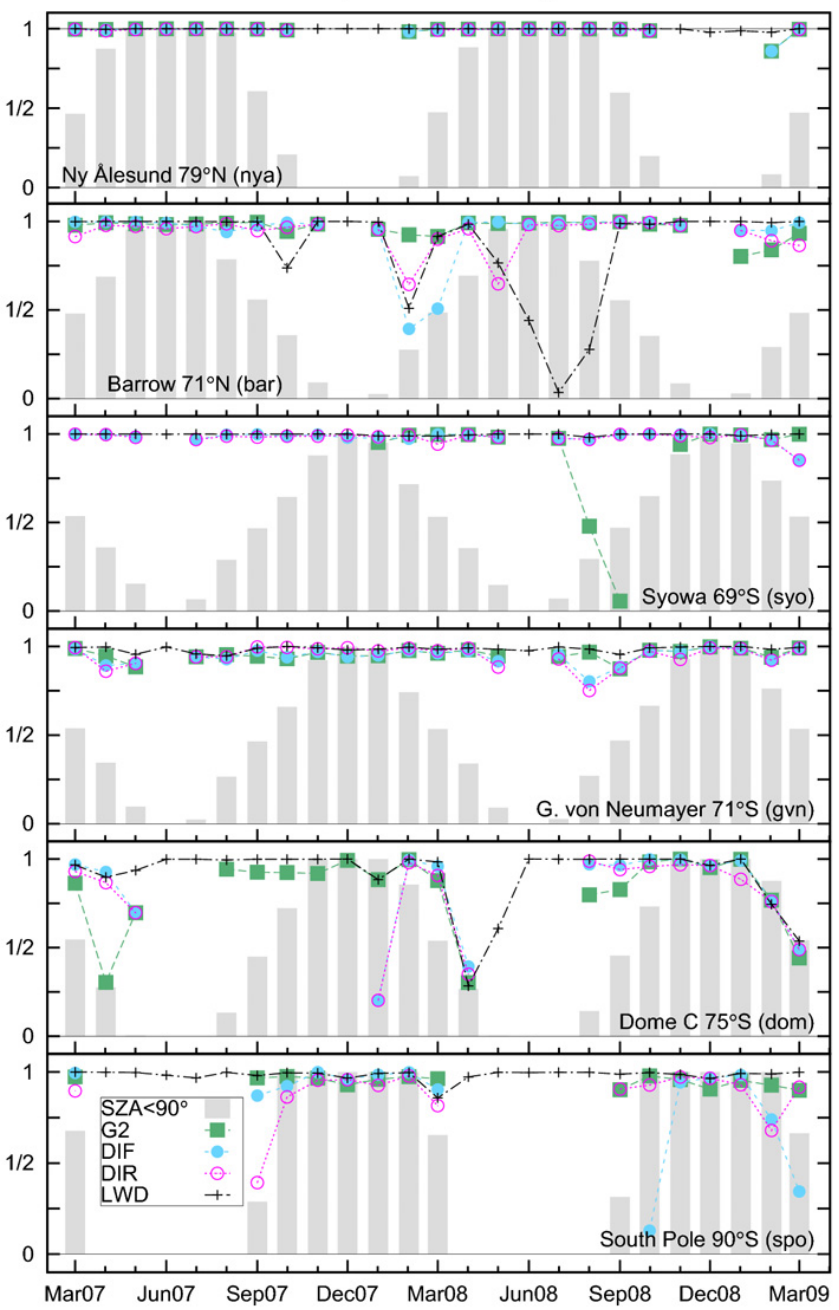

Figure 3. Monthly availability of the BSRN data for downwelling global shortwave (G2), direct (DIR), diffuse (DIF) and longwave downwelling (LWD) radiation components. The lack of a marker corresponds to lack of corresponding data. Fractions for shortwave components are calculated with respect to the daylight $\left(\mathrm{SZA}<90^{\circ}\right)$, while for longwave with respect to all-day. Gray bars indicate the daylight fraction for various months of the IPY measurement period from March 2007 to March 2009.

Monitoring Center but are recommended by the BSRN for the station managers who are responsible for the data quality of their station. The QC tests involve physically-possible and climatological extremely rare limit checks, along with tests for consistency between measurements. Also comparison of the various components with radiative transfer calculations is suggested as a useful tool for station leaders for data evaluation and interpretation. A final visual inspection of the time series of irradiances in various time resolutions and combinations with other information, is considered an effective test when performed by experienced analysts (Ohmura et al., 1998; Long and Shi, 2008; Long and Dutton, 2002).
Table 3. Quality checks as defined in the BSRN guidelines. The lower physically possible $\left(p p l_{1}\right)$ and extremely rare $\left(e r l_{1}\right)$ limits, and the corresponding upper bounds $\left(p p l_{\mathrm{u}}\right.$ and $\left.e r l_{\mathrm{u}}\right)$ are defined for the following radiative components: (G2) downwelling global shortwave measured by the pyranometer, (DIF) diffuse shortwave, $\left(\mathrm{DIR}_{\perp}\right)$ direct normal shortwave, (LWD) downwelling longwave, (LWU) upwelling longwave and (SWU) reflected shortwave radiations. $\mathrm{S}$ is the solar radiative flux at the top of the atmosphere defined by $S=r_{0}^{2} / r^{2} S_{\text {a }}$, being $S_{\mathrm{a}}=1368 \mathrm{~W} / \mathrm{m}^{2}$ the solar constant at the mean earth-sun distance $r_{0} . \mu$ is the cosine of the solar zenith angle $\theta$. All values in $\mathrm{W} / \mathrm{m}^{2}$.

\begin{tabular}{lccll}
\hline Quantity & $p p l_{1}$ & erl $_{1}$ & erl & $p p l_{\mathrm{u}}$ \\
\hline G2 & -4 & -2 & $1.20 S \mu^{1.2}+50$ & $1.50 S \mu^{1.2}+100$ \\
DIR $_{\perp}$ & -4 & -2 & $0.95 S \mu^{1.2}+10$ & 1368 \\
DIF & -4 & -2 & $0.75 S \mu^{1.2}+30$ & $0.95 S \mu^{1.2}+50$ \\
SWU & -4 & -2 & $S \mu^{1.2}+50$ & $1.2 S \mu^{1.2}+50$ \\
LWD & 40 & 60 & 500 & 700 \\
LWU & 40 & 60 & 700 & 900 \\
\hline
\end{tabular}

Table 4. Across quantity as defined in the BSRN guidelines. G2 is the SWD measured by the pyranometer. G1 is the SWD obtained as sum of diffuse and direct components. $S_{\mathrm{a}}=1368 \mathrm{~W} / \mathrm{m}^{2}$ is the solar constant that should be scaled according to the earth-sun distance, while $\mu$ is the cosine of the solar zenith angle $\theta$. Values involving LWD are expressed in $\mathrm{W} / \mathrm{m}^{2}$, the others are dimensionless.

\begin{tabular}{lcc}
\hline Comparison & lower limit & upper limit \\
\hline G2/G1 $\left(\theta<75^{\circ}\right)$ & 0.92 & 1.08 \\
G2/G1 $\left(\theta>75^{\circ}\right)$ & 0.85 & 1.15 \\
DIF/G2 & - & $<1.05$ \\
DIF/G2 & - & $<1.10$ \\
SWU/G1(or G2) & $<1.0$ & $<1.0$ \\
LWD (to $\left.T_{\mathrm{a}}\right)$ & $0.4 \sigma T_{\mathrm{a}}^{4}$ & $\sigma T_{\mathrm{a}}^{4}+25$ \\
LWU (to $\left.T_{\mathrm{a}}\right)$ & $\sigma\left(T_{\mathrm{a}}-15\right)^{4}$ & $\sigma\left(T_{\mathrm{a}}+25\right)^{4}$ \\
LWD-LWU & -300 & +25 \\
\hline
\end{tabular}

The applied physically possible $(p p l)$ and extremely rare limits (erl) are given in Table 3, while comparison tests are listed in Table 4. A subset of the QC tests were applied to the downwelling components of the IPY-BSRN dataset, and results reported as follows. All ppl and erl checks were applied, along with the across quantities including: (a) ratio between G1 and G2, (b) the diffuse to global ratio (result not reported here), and (c) the longwave (LWD) to air temperature $T_{\mathrm{a}}$ equivalent blackbody irradiance comparison. 


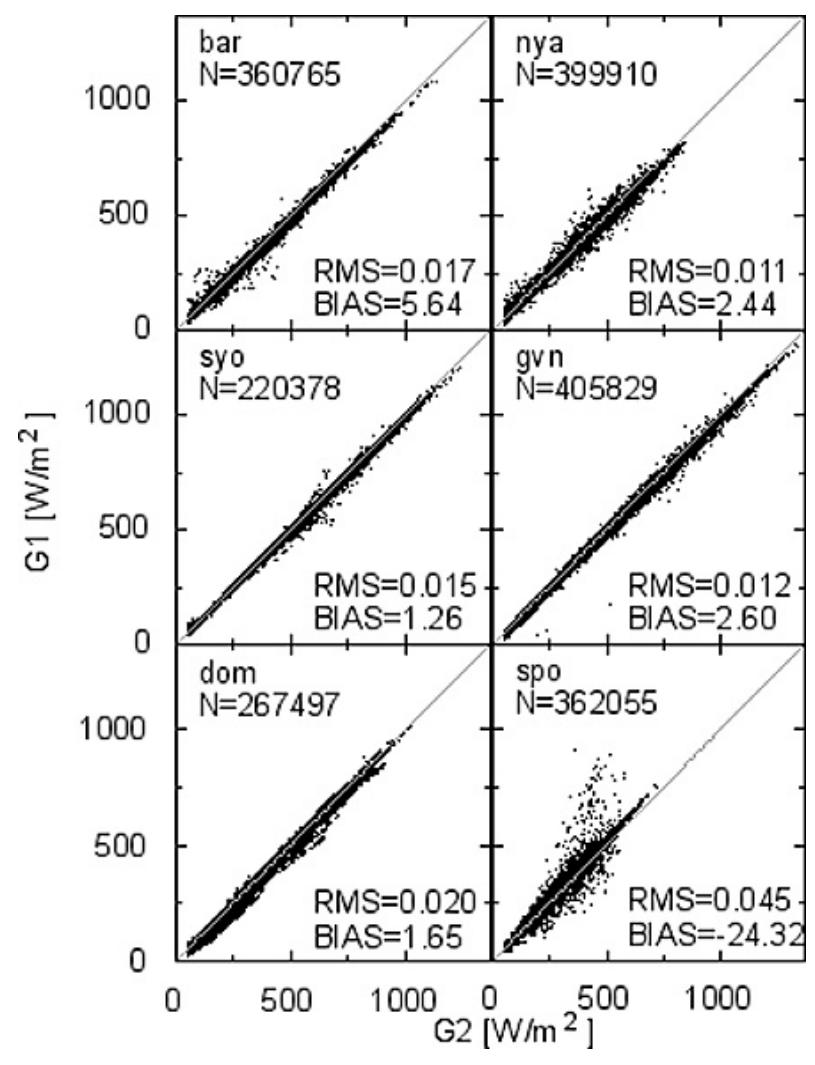

Figure 4. (Left) Comparison between the global radiation measured by the pyranometer (G2) and the sum of direct and diffuse radiation (G1). The cloud of points for spo that stay away from the bisector, originate from a hundred points on 1 January 2009.

The BSRN guidelines clearly indicate that erl should be defined according to an appropriate climatology of the site, therefore, values valid for one station are not necessarily applicable to another. Nevertheless, in this framework, the values indicated by Long and Dutton (2002), were adopted for the definition of the extremely rare limits. For example, the lower longwave erl $\left(+60 \mathrm{~W} / \mathrm{m}^{2}\right)$ was observed at Dome $\mathrm{C}$ many times $(12 \%)$, with the 10 th percentile of $58 \mathrm{~W} / \mathrm{m}^{2}$ and median value of $79 \mathrm{~W} / \mathrm{m}^{2}$ and a 90 th percentile of $98 \mathrm{~W} / \mathrm{m}^{2}$. A more similar station, but at a lower elevation, is spo that has a 10th percentile of $82 \mathrm{~W} / \mathrm{m}^{2}$, a median of $108 \mathrm{~W} / \mathrm{m}^{2}$ and a 90 th percentile of $158 \mathrm{~W} / \mathrm{m}^{2}$.

The direct normal component exceeded the extremely rare limit checks by nya and gvn stations mainly during the early and late summer (although at rate always less than $5 \%$ per month); diffuse component exceeded the limit less than the $5 \%$ of the time at spo, gvn and nya. This is likely related to the high reflectance of the polar surfaces that, in conjunction with scattered clouds, can enhance the diffuse component with respect to locations with a lower surface albedo. These data are not necessarily in error, because worldwide typical limits were applied. These data should be used with care and could be subjected to further investigation by the BSRN-IPY

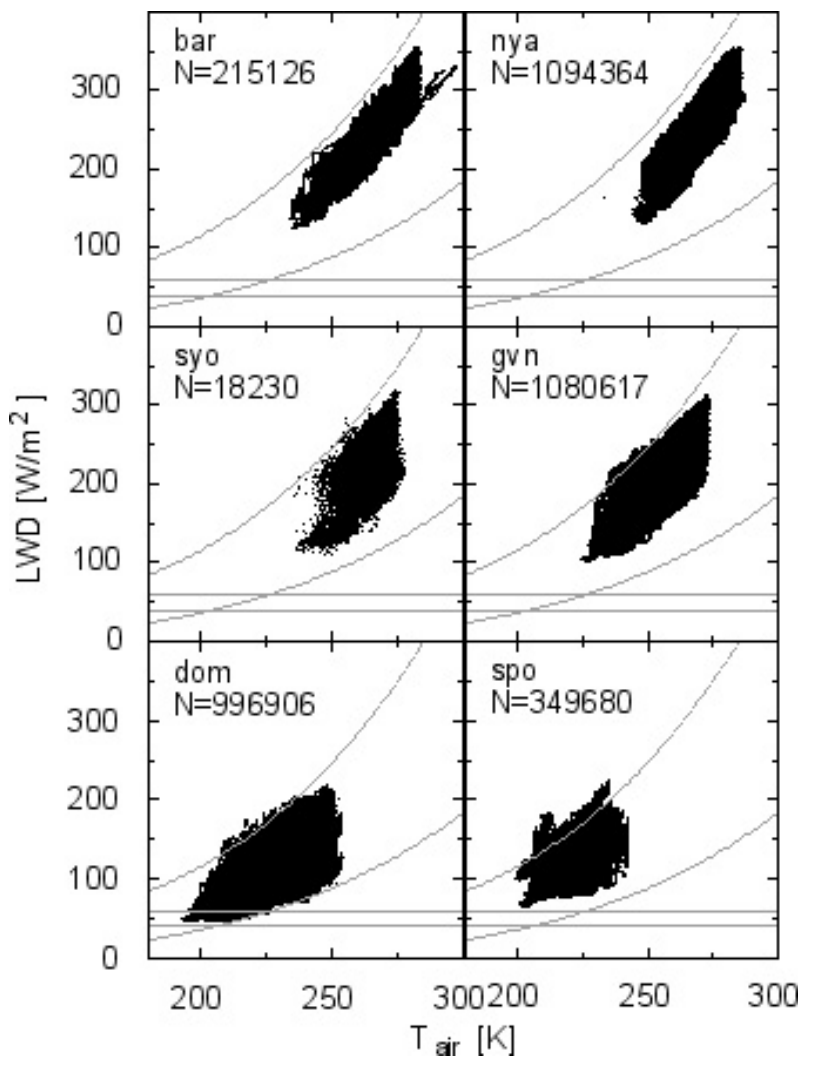

Figure 5. Downwelling Longwave to air temperature comparison. Horizontal lines represent the lower extremely rare limit erl (upper one) and the lower physically possible limit $p p l_{1}$. Curves represent the lower and the upper limits of downwelling longwave LWD to air temperature $T_{\mathrm{a}}$ comparison (see Table 4).

data users. A comparison of G1 and G2 for all sites included in the dataset was performed and the result represented in Fig. 4. For each station, the root mean square calculated for the pair with $\mathrm{G} 2$ greater than $+50 \mathrm{~W} / \mathrm{m}^{2}$, was calculated. They varied between a minimum of 0.011 for nya to a maximum of 0.045 for spo. A significant bias $\left(1 / N \sum[\mathrm{G} 1-\mathrm{G} 2]\right)$, was observed for spo $\left(-24 \mathrm{~W} / \mathrm{m}^{2}\right)$, while for the other station the bias was observed to be consistent with absolute error expected. The anomaly at spo is due to the erroneous cluster of points well above the 1:1 line most likely due to diffuse tracker failure, which has been isolated to the December 2008 to March 2009 time period. The maximum values of SW global radiation were observed in sites with the lower latitude (higher solar elevation), being the southern sites reaching values up to $1300 \mathrm{~W} / \mathrm{m}^{2}$.

Figure 5 shows the downwelling longwave LWD to air temperature $T_{\mathrm{a}}$ comparison, for all stations. This test is formulated considering that an effective atmospheric emittance - defined as $\epsilon_{\mathrm{A}}=\mathrm{LWD} / \sigma T_{\mathrm{a}}^{4}-$ of no less than 0.4 should be considered valid. On the other hand a longwave component greater than a black-body emission at surface air temperature, is considered highly improbable. Although this 


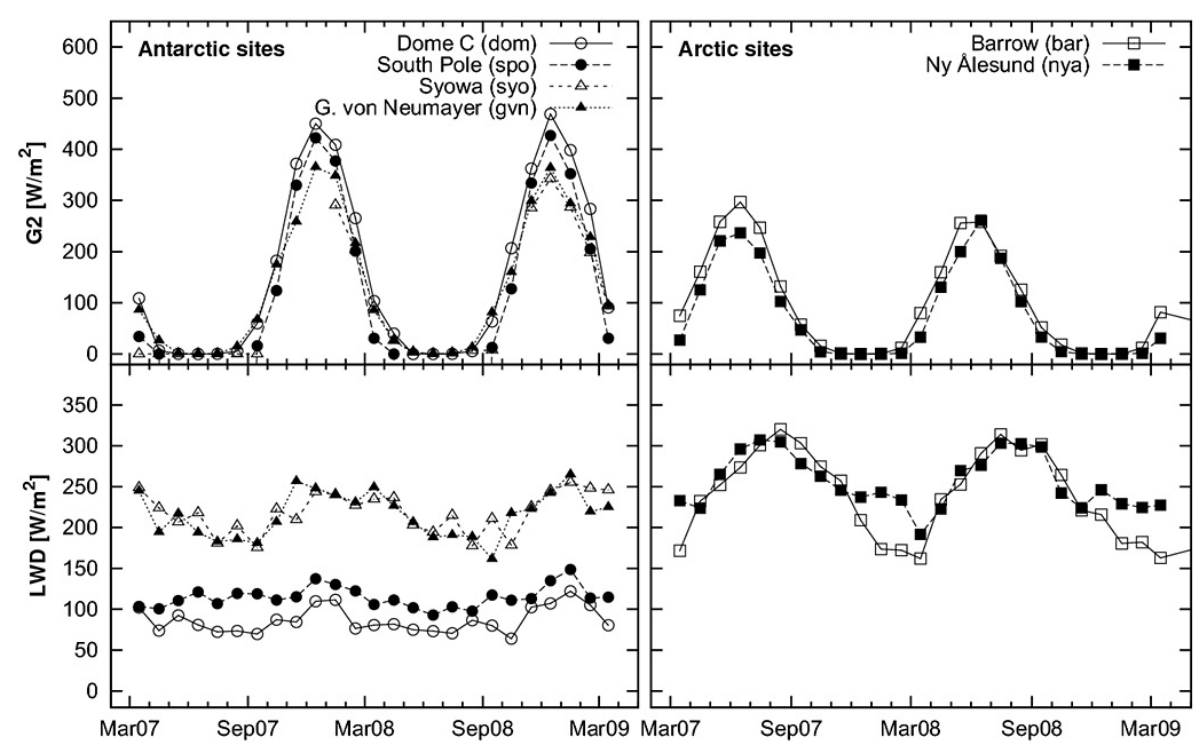

Figure 6. Monthly means of global downwelling shortwave G2, and downwelling longwave radiation LWD for the Antarctic (left) and Arctic stations (right). G1 is used to fill periods uncovered by G2.

typically hold true for mid-latitude sites, in polar regions a combination of temperature inversion and thick cloudiness, could enhance the effective emissivity of the atmosphere inducing measurements of several $\mathrm{W} / \mathrm{m}^{2}$ greater than this limit (König-Langlo and Augstein, 1994). This likely explains why all the Antarctic sites often exceed the upper limit, but at different rates of occurrance, while passing all $\mathrm{ppl}$ and $\mathrm{erl}$ tests on the longwave component.

A data summary consisting of monthly averages for downwelling global (G2) and longwave are given in Fig. 6. It is apparent that the solar geometry and cloudiness dominate the solar results. At coastal sites, downwelling longwave ranges between $170 \mathrm{~W} / \mathrm{m}^{2}$ during clear sky late winter months to $250 \mathrm{~W} / \mathrm{m}^{2}$ in Antarctic summer and to $300 \mathrm{~W} / \mathrm{m}^{2}$ in Arctic, consistent with an expected greater occurrence of thicker clouds in Arctic regions. The time patterns of the global and longwave monthly averages relative to Barrow site, appear to be consistent with a 10-year climatology given by Dong et al. (2010).

Acknowledgements. The field acquisition of the data reported here was possible because of various research projects funded by many national institutions, including: The Alfred Wegener Institute (nya and gvn), the National Oceanic and Atmospheric Administration (bar and spo), the Programma Nazionale di Ricerche in Antartide (dom), the National Institute of Polar Research and the Japan Meteorological Agency (syo). Special acknowledgment is given to all people contributing to the maintenance of the hardware and software infrastructure as well as to the improvement of the data quality of the BSRN network.

\section{References}

Dutton, E. G.: Tenth session of the baseline surface radiation network (BSRN), De Bilt, The Netherlands, 7-11 July, 2008, WCRP Informal report No. 11/2008, available at: http://wcrp. wmo.int/documents/bsrn10_report.pdf, 2008.

Dutton, E. G. and Erlich, D.: 11th BSRN Scientific Review and Workshop Queenstown, New Zealand, 13-16 April 2010, available at: http://gewex.org/images/BSRN-11summary.pdf, 2010.

Dong, X., Xi, B., Crosby, K., Long, C.N., Stone, R. and Shupe M.: A 10-yr Climatology of Arctic Cloud Fraction and Radiative Forcing at Barrow, Alaska, J. Geophys. Res., 115, D17212, doi:10.1029/2009JD013489, 2010.

Hegner, H., Müller, G., Nespor, V., Ohmura, A., Steigrad R., and Gilgen H.: Technical Plan for BSRN Data Management - 1998 Update, WMO/TD-No. 882, WCRP/WMO, 1998.

Heimo, A., Vernez, A., and Wasserfallen, P.: Baseline Surface Radiation Network (BSRN), Concept and Implementation of a BSRN Station, WMO/TD-No. 579, WCRP/WMO, 1993.

König-Langlo, G. and Augstein, E.: Parameterization of the downward long-wave radiation at the Earth's surface in polar regions, Meteorol. Z., N.F.3, H. 6, 343-347, 1994.

Long, C. N. and Dutton, E. G. : BSRN Global Network recommended QC tests, V2.0, BSRN Technical Report, 2002.

Long, C. N. and Shi, Y.: An Automated Quality Assessment and Control Algorithm for Surface Radiation Measurements, The Open Atmospheric Science Journal, 2, 23-27, 2008.

McArthur, L. J. B.: Baseline Surface Radiation Network (BSRN), Operations Manual, WMO/TD-No. 879, WCRP/WMO, 2004.

McArthur, L. J. B.: Baseline Surface Radiation Network (BSRN), Operations Manual Version 2.1, WMO/TD-No. 1274, WCRP/WMO, 2005. 
Michalsky, J. J.: The astronomical almanac's algorithm for approximate solar position (1950-2050), Sol. Energy, 40, 227-235, 1988.

Ohmura, A., Dutton, E. G., Forgan, B., Frohlich, C., Gilgen, H., Hegner, H., Heimo, A., König-Langlo, G. McArthur, B., Muller, G., Philipona, R., Pinker, R., Whitlock, C.H., Dehne, K., and Wild, M.: Baseline Surface Radiation Network (BSRN/WRMC), a new precision radiometry for climate research, B. Am. Meteorol. Soc., 79, 2115-2136, 1998.

Philipona, R., Frohlich, C., and Betz, C. H.: Characterisation of pyrgeometers and accuracy of atmospheric long-wave radiation measurements, Appl. Opt., 34, 9, 1598-1605, 1995. 